\title{
OIL OF CITRON.
}

By Herbert E. Burgess.

(Read at the Meeting, May 1, 1901.)

OwIng to the extensive adulteration of citron oil, considerable doubt attaches to many of the published numbers representing its physical and chemical constants. A sample of the oil of undoubted genuineness having been placed at my disposal, it occurred to me that the results which I have obtained on its examination might possibly be of interest and use to the members of the Society.

There has always been considerable confusion between lemon and citron oil, as in France and Sicily lemon oil is known as "Essence de Citron," while citron is known as "Essence de Cedrat."

Citron oil is stated to be expressed from the rind of Citrus medica risso; but, in fact, a smaller variety of the fruit is used, the true citron fruit being used almost exclusively for the production of candied peel.

It is generally known that the majority of citron oil sent to this country is nothing more than a mixture of lemon oil with verbena, and, in some cases, a small quantity of otto of roses is used as a sweetening agent.

The oil referred to above gave on examination the following constants:

Specific gravity, $15^{\circ} \mathrm{C}$., $0 \cdot 8513$

Refractive index, $[\mathrm{N}]_{\mathrm{D}}, 20^{\circ}$ C., 1.4750

Optical rotation, $[\alpha]_{\mathrm{D}}, 100 \mathrm{~mm} .+80^{\circ} 13^{\prime}$

On distilling the oil at a pressure of 10 millimetres, the following fractions were obtained :

$$
\begin{array}{llllcll}
\text { 1. } 60-62^{\circ} & \ldots & \ldots & \ldots & 12 \text { per cent. rotation }+86^{\circ} 30^{\prime} \\
\text { 2. } 62-64^{\circ} & \ldots & \ldots & \ldots & 80 & \text { rotation }+85^{\circ} 30^{\prime} \\
\text { 3. } 64-85^{\circ} & \ldots & \ldots & \ldots & 5 & \text {, } & \text { rotation }+13^{\circ} 30^{\prime}
\end{array}
$$


Numbers 1 and 2 were refractionated and distilled several times over clean sodium to remove any oxygenated constituents. The main fraction thus obtained was identified as limonene, boiling at $173^{\circ}$ to $174^{\circ} \mathrm{C}$. at atmospheric pressure, and having a rotation of $+89^{\circ}$. Possibly with this fraction there was a small percentage of the dipentene, which would account for the rotation being somewhat lower than is generally given for limonene, but I was unable to make any further separation.

The third fraction was examined for citral by Tiemann's cyanacetic acid reagent, and I obtained the well-defined citralidene-cyanacetic acid, having a meltingpoint of $120^{\circ}$ to $121^{\circ} \mathrm{C}$.

With the mercuric sulphate reagent, as described in the ANaLyst, vol. xxv., p. 265 , it gave the blood-red coloration peculiar to citral.

A determination of the citral in the original oil gave the following figures:

By sodium bisulphite method (i.) 6.2 per cent.; (ii.) 5.8 per cent.

By hydroxylamine method, $5 \cdot 7$ per cent.

The original oil had a considerable deposit of resinous and crystalline matter, which was filtered off and extracted with chloroform; on standing crystals were formed which were filtered off and dissolved in petroleum spirit to free them from resinous matter. The crystals thus obtained were finally recrystallized from alcohol. Well-formed needle-shaped crystals were obtained, having a melting-point of $145^{\circ} \mathrm{C}$., with a marked blue fluorescence in alcoholic solution. The crystals were soluble in alcoholic potash and reprecipitated by acids ; quite neutral to litmus ; slightly soluble in boiling water, from which they crystallized out on cooling; soluble in strong sulphuric acid. Boiling Fehling's solution was not reduced by them.

$\begin{array}{cccccr}\text { Two combustions gave : } & & & & \text { I. } & \text { II. } \\ \text { Carbon } & \ldots & \ldots & \ldots & 64 \cdot 77 & 64 \cdot 88 \\ \text { Hydrogen } & \ldots & \ldots & \ldots & 5 \cdot 40 & 5 \cdot 24 \\ \text { Oxygen } & \ldots & \ldots & \ldots & 29 \cdot 83 & 29 \cdot 88\end{array}$

Molecular weight determination gave 355 , corresponding with a formula: $\mathrm{C}_{18} \mathrm{H}_{18} \mathrm{O}_{6}$.

I believe this substance to be identical with that observed by Crismer, and more recently by Theulier.

The following table gives my results and those of other workers.

$\begin{array}{llllccc} & & \begin{array}{l}\text { Specific } \\ \text { Gravity. }\end{array} & \text { Rotation. } & \text { Boiling-point. } & \text { Citral. } & \begin{array}{c}\text { Refractive } \\ \text { Index. }\end{array} \\ \text { Sample A } & \ldots & 0.8513 & +80^{\circ} 13^{\prime} & 60^{\circ}-100^{\circ}(10 \mathrm{~mm} .) & 6 \% & 1.4750 \\ \text { Sample B } & \ldots & 0.8568 & +70^{\circ} 13^{\prime} & 58^{\circ}-90^{\circ}(10 \mathrm{~mm} \text {. } & 5 \% & 1.4755 \\ \text { Gildemeister... } & 0.8710 & +67^{\circ} & 8^{\prime} & 177^{\circ}-220^{\circ} & & \\ \text { Charabot } & \ldots & 0.8700 & +67^{\circ} 0^{\prime} & 177^{\circ}-220^{\circ} & & \\ \text { Parry... } & \ldots & 0.86-0.87 & +66^{\circ}-76^{\circ} & & & \end{array}$

Sample A represents the genuine oil spoken of above.

Sample B was an oil obtained from another source, and guaranteed to be pure, but on examination it was found to be adulterated with a considerable quantity of lemon oil.

It will be seen at once, by referring to the above table, that the physical con- 
stants of a genuine citron oil are widely different from the oils examined by different workers.

I understand that citron oil is only expressed in Sicily to special order.

\section{Discussion.}

Dr. Morris asked if the white, needle-shaped crystals referred to were found in the oil itself.

Mr. BuRGEss said that the oil, as he received it, contained a considerable deposit, which had been filtered off, and from this the crystals were extracted.

Dr. Morris said that some years previously (Journ. Chem. Soc., 1882), in the course of an investigation in connection with the hydrocarbons occurring in resin spirit, he had found in certain samples crystalline needles which behaved with acid similarly to those described by Mr. Burgess, and which he had identified as heptene glycol.

Mr. Chapman said that an important point in connection with this sample was the fact that its rotation was, he believed, some $10^{\circ}$ or $12^{\circ}$ higher than the highest recorded number for citron oil. The boiling-point of the sample was very much lower than those recorded by Gildemeister and one or two other observers, though it was somewhat doubtful whether any real comparison could be made with these figures, because they represented merely the boiling-points between which the main fraction distilled, whereas those of Mr. Burgess represented the total range from minimum to maximum.

Mr. BuRGess said that he had never observed in lemon oil a rotation of over $67^{\circ}$, whereas in this particular oil it was over $80^{\circ}$, or $10^{\circ}$ higher than the highest recorded for lemon oil. The specific gravity, of course, was very much lower. The references to the range of boiling-point in the different works on the subject did not indicate at what pressure the boiling-points were determined, but it was probably at atmospheric pressure. The whole range from beginning to end would be taken. Any one particular fraction would have a much smaller range. 